\section{ASSOCIATIONS BETWEEN DAILY SLEEP AND AFFECTIVE EXPERIENCES: A SYSTEMATIC REVIEW}

Robert Hickman*, Teresa C D'Oliveira. King's College London (Academic Psychiatry), London, UK

\subsection{6/bmiresp-2021-bssconf.30}

Introduction This work reviews empirical research investigating the bidirectional relationship between daily sleep and affective experiences. In particular, the review focuses on ambulatory assessments such as experience sampling (ESM) and daily diaries. A secondary objective explored the differential impact of affective disorder diagnosis and shift work on daily sleep-emotion dyads.

Methods EMBASE (Ovid), Ovid MEDLINE(R), PsycINFO (Ovid), and Scopus (Elsevier) were searched to January 2021. Additional studies were identified through reference checking and hand searching. Records were deduplicated on EndNote and uploaded to Rayyan.

Results 1526 studies were identified and 51 met the full inclusion criteria. Studies predominantly included healthy populations $(\mathrm{N}=42)$, of which four involved shift workers; remaining studies investigated mood disorders $(\mathrm{N}=9)$. Studies with only self-report sleep measures were most common $(\mathrm{N}=31)$ but a high number incorporated actigraphy $(\mathrm{N}=20)$. Overall, 13 studies used both actigraphy (objective) and selfreport (subjective) sleep markers. Sleep diaries $(\mathrm{N}=13)$, the Pittsburgh Sleep Quality Index (PSQI; N=10), and Positive and Negative Affect Schedule (PANAS; $\mathrm{N}=20$ ) were the most widely used measures. In general, findings support a mutual relationship between sleep and next-day affective experiences among healthy populations and individuals diagnosed with a mood disorder.

Discussion This work expands on prior reviews by Konjarski, Murray, Lee, and Jackson (2018) and Ong, Kim, Young, and Steptoe (2017) across four areas: to include affective disorders and shift workers; to focus on the situational context of daily assessments; to account for interchangeable affective definitions; and to include studies published after 2017.

\section{REFERENCES}

1. Konjarski M, Murray G, Lee $V$ V, \& Jackson ML. Reciprocal relationships between daily sleep and mood: A systematic review of naturalistic prospective studies. Sleep Medicine Reviews 2018;42:47-58. doi:https://doi.org/10.1016/j. smrv.2018.05.005

2. Ong AD, Kim $S$, Young $S$, \& Steptoe A. Positive affect and sleep: A systematic review. Sleep Med Rev 2017;35:21-32. doi:10.1016/j.smrv.2016.07.006

\section{MANAGEMENT OF CENTRAL APNOEAS - ANALYSIS OF A PAEDIATRIC COHORT REFERRED TO A TERTIARY CARE SLEEP SERVICE}

${ }^{1}$ Sairah Akbar*, 'Ridma Jayarathna, ${ }^{1}$ Siobhan Kenny, ${ }^{1}$ Hannah Williams, ${ }^{1}$ Alex Thomas, ${ }^{1}$ Sakina Dastagir, ${ }^{1}$ Ruth O'Reilly, ${ }^{1}$ Rishi Pabary, ${ }^{1}$ Hui-Leng Tan, ${ }^{2}$ Federica Trucco. 'Department of Paediatric Sleep and Ventilation/Respiratory Medicine, Royal Brompton Hospital, London, UK; ${ }^{2}$ Department of Paediatric Neuroscience, Guy's and St Thomas' NHS trust and Department Paediatric Respiratory medicine, Royal Brompton Hospital, London, UK

\subsection{6/bmjresp-2021-bssconf.31}

Introduction Central sleep apnoea (CSA) is common in childhood and is usually clinically associated with developmental delay, syndromes, brain and/or brainstem involvement. The threshold for significant CSA remains controversial. Only one study so far has described CSA in a large paediatric cohort. ${ }^{1}$

The aim of this study was to review the prevalence, clinical correlation and management of CSA in a cohort of paediatric patients referred to a tertiary UK sleep service.

Methods Retrospective study of children $<18$ years referred to the paediatric sleep service for a sleep study between April 2018-July 2020. We included patients with a cAHI of $\geq 1$. Patients with previous sleep studies, diagnosis of CSA and on ventilatory support or oxygen therapy were excluded.

Results 162 patients were included with a median age of 2.7 years (range 9 days to 9.7 years). 129 patients had isolated cAHI of 1-5 without association with obstructive sleep apnoea (OSA), defined as oAHI $>5$. 14 had isolated $\mathrm{cAHI} \geq 5$ and 19 had CSA with OSA.

Abstract 35 Table 1 Background and severity of CAHI

\begin{tabular}{|c|c|c|c|}
\hline Diagnoses & $\begin{array}{l}\text { Isolated CSA with } \\
\text { cAHI 1-5 }\end{array}$ & $\begin{array}{l}\text { Isolated CSA with } \\
\text { cAHI>5 }\end{array}$ & CSA with OSA $>5$ \\
\hline Congenital heart disease & $8(6.0 \%)$ & & $3(15.8 \%)$ \\
\hline PWS Pre-GH & $6(4.5 \%)$ & $1(10 \%)$ & \\
\hline PWS Post-GH & $1(0.8 \%)$ & & \\
\hline Trisomy 21 & $6(4.5 \%)$ & $1(10 \%)$ & $1(5.3 \%)$ \\
\hline Ex-preterm & $13(9.8 \%)$ & $2(20 \%)$ & $2(10.5 \%)$ \\
\hline Chronic lung disease & $2(1.5 \%)$ & & \\
\hline Unsafe swallow & $3(2.3 \%)$ & & $1(5.3 \%)$ \\
\hline Obesity/overweight & $4(3.0 \%)$ & & $3(15.8 \%)$ \\
\hline Neurodisability/neuromuscular including seizures & $9(6.8 \%)$ & $2(20 \%)$ & $3(15.8 \%)$ \\
\hline Congenital syndromes & $3(2.3 \%)$ & $2(20 \%)$ & \\
\hline Recurrent lower respiratory tract infections & $4(3.0 \%)$ & & $1(5.3 \%)$ \\
\hline Adenotonsillar hypertrophy/symptoms osa & $59(44.4 \%)$ & $2(20 \%)$ & $9(47.4 \%)$ \\
\hline Asthma/VIW/bronchiolitis & $24(18.0 \%)$ & $1(10 \%)$ & $2(10.5 \%)$ \\
\hline Gastro-oesophageal reflux disease & $3(2.3 \%)$ & $1(10 \%)$ & $1(5.3 \%)$ \\
\hline Miscellaneous & 11 (8.3\%) & & $3(15.8 \%)$ \\
\hline
\end{tabular}

